\title{
Characterization of the symptoms of neurogenic orthostatic hypotension and their impact from a survey of patients and caregivers
}

Daniel O. Claassen ${ }^{1 *}$, Charles H. Adler ${ }^{2}$, L. Arthur Hewitt ${ }^{3}$ and Christopher Gibbons ${ }^{4}$

\begin{abstract}
Background: Neurogenic orthostatic hypotension $(\mathrm{nOH})$ results from impaired vasoconstriction due to dysfunction of the autonomic nervous system and is commonly associated with Parkinson disease (PD), multiple system atrophy (MSA), and pure autonomic failure. $\mathrm{nOH}$ can increase the risk of falls due to symptoms that include postural lightheadedness or dizziness, presyncope, and syncope. The purpose of this study was to obtain information from patients and caregivers regarding the symptoms and burden of $\mathrm{nOH}$ to expand on limited knowledge regarding the impact of $\mathrm{nOH}$ on quality of life.
\end{abstract}

Methods: This author-designed survey included questions regarding $\mathrm{nOH}$ (e.g., frequency and impact of symptoms, management) and was conducted online by Harris Poll via distribution to individuals who agreed to participate in Harris Poll online surveys or who were members of relevant disease advocacy organizations. Eligible patients were aged $\geq 18$ years with $P D, M S A$, or pure autonomic failure and $\geq 1$ of the following: orthostatic hypotension $(\mathrm{OH})$, $\mathrm{nOH}$, low blood pressure upon standing, or $\mathrm{OH} / \mathrm{nOH}$ symptoms. Eligible caregivers cared for such patients but were not necessarily linked to any patient participant.

Results: Survey responses were received from 363 patients and 128 caregivers. PD was the most frequent underlying disorder ( $90 \%$ of patients; $88 \%$ of individuals managed by the caregivers). Despite meeting survey diagnosis criteria, a formal diagnosis of $\mathrm{OH}$ or $\mathrm{nOH}$ was reported by only $36 \%$ of patients and $16 \%$ of caregivers. The most frequent symptoms of $\mathrm{nOH}$ were dizziness or lightheadedness, fatigue when standing, and difficulty walking. A negative impact on patient quality of life caused by $\mathrm{nOH}$ symptoms was reported by $59 \%$ of patients and $75 \%$ of caregivers. Most respondents $(\geq 87 \%)$ reported that $\mathrm{nOH}$ symptoms adversely affected patients' ability to perform everyday activities (most frequently physical activity/exercise, housework, and traveling). Falls $(\geq 1)$ in the previous year due to $\mathrm{nOH}$ symptoms were reported by $57 \%$ of patients and $80 \%$ of caregivers.

Conclusions: These survey results support the premise that nOH symptoms have a substantial negative impact on patient function and quality of life. The relatively low rates of formal $\mathrm{nOH} / \mathrm{OH}$ diagnosis suggest the need for heightened awareness regarding the condition and its symptom burden.

Keywords: Neurogenic orthostatic hypotension, Parkinson disease, Multiple system atrophy, Quality of life, Disease burden

\footnotetext{
* Correspondence: Daniel.claassen@vanderbilt.edu

${ }^{1}$ Department of Neurology, Vanderbilt University Medical Center, 1161 21st

Avenue South A-0118, Nashville, TN 37232, USA

Full list of author information is available at the end of the article
}

(c) The Author(s). 2018 Open Access This article is distributed under the terms of the Creative Commons Attribution 4.0 International License (http://creativecommons.org/licenses/by/4.0/), which permits unrestricted use, distribution, and reproduction in any medium, provided you give appropriate credit to the original author(s) and the source, provide a link to the Creative Commons license, and indicate if changes were made. The Creative Commons Public Domain Dedication waiver (http://creativecommons.org/publicdomain/zero/1.0/) applies to the data made available in this article, unless otherwise stated. 


\section{Background}

Orthostatic hypotension $(\mathrm{OH})$ is defined as a sustained reduction in systolic blood pressure (BP) of $\geq 20 \mathrm{mmHg}$ or in diastolic BP of $\geq 10 \mathrm{mmHg}$ upon standing [1]. $\mathrm{OH}$ generally results from 3 common etiologies: (1) medications such as antidepressants or antihypertensive agents, (2) non-neurologic conditions such as hypovolemia or cardiovascular disorders causing cardiac failure, or (3) impaired vasoconstriction due to dysfunction of the autonomic nervous system (also referred to as neurogenic $\mathrm{OH}[\mathrm{nOH}]$ ). The neurogenic form of $\mathrm{OH}$ is commonly associated with neurodegenerative disorders that affect the central or peripheral autonomic nervous system, such as Parkinson disease (PD), multiple system atrophy (MSA), and pure autonomic failure, or it may be secondary to conditions such as diabetic peripheral neuropathy [1-6]. Although differential diagnosis is often challenging, $\mathrm{nOH}$ can be distinguished from non-neurogenic forms of $\mathrm{OH}$, such as medication effects and volume depletion, through autonomic testing $[5,7]$. Common symptoms of $\mathrm{nOH}$ include postural lightheadedness or dizziness, presyncope, falls, and syncope $[1,5]$. Additional symptoms can include visual disturbances, fatigue, generalized weakness, cognitive dysfunction, neck pain or discomfort in the suboccipital and paracervical region (i.e., in a "coat hanger" configuration), and orthostatic dyspnea $[1,5]$.

Neurogenic $\mathrm{OH}$ can increase the risk of falls, particularly among older patients $[8,9]$. However, only limited information regarding the impact of $\mathrm{nOH}$ on quality of life among patients and caregivers has been published [1012]. We designed a survey to gain a better understanding of the following areas: (1) scope of symptoms and burden of disease among patients with $\mathrm{nOH}$, (2) effect of $\mathrm{nOH}$ symptoms on lives of patients from the perspective of caregivers, and (3) insights on the patient and caregiver journey from diagnosis to symptom management.

\section{Methods}

A survey designed by the authors was conducted online by Harris Poll on behalf of Lundbeck between August 26, 2016, and October 3, 2016. Respondents for the survey included individuals who agreed to participate in Harris Poll online surveys or who are members of certain advocacy organizations (American Parkinson Disease Association, Davis Phinney Foundation, Michael J. Fox Foundation, MSA Coalition, National Parkinson Foundation, and Parkinson's Disease Foundation) who also met eligibility criteria and agreed to participate in the current survey. For research in which participants are intended to remain anonymous, Harris Poll uses tools and methods to ensure that there is no reasonable possibility of identifying an individual participant in the reports created (e.g., individual responses collected are combined to produce "aggregated" reports). Eligible patient participants were US residents aged $\geq 18$ years who self-selected a diagnosis of PD, MSA, or pure autonomic failure based on a diagnosis received from their treating physicians. Individuals also met $\geq 1$ of the following criteria: (1) received a formal diagnosis of $\mathrm{OH}$ or $\mathrm{nOH}$, (2) were informed by a health care provider that their symptoms are caused by low blood pressure or a sudden drop in blood pressure upon standing, or (3) experience the following upon sitting up, standing up, standing for long periods of time, or with a change in position: 2 or more listed $\mathrm{OH} / \mathrm{nOH}$ symptoms at least every time, daily, weekly, monthly, or a few times a year and at least 1 of the following symptoms: dizziness or lightheadedness, feeling faint, or fainting. Because of the underlying neurologic diagnosis criteria, eligible patient responders were presumed to have "nOH" for the purposes of this study, even if they did not receive a formal diagnosis. Eligible caregiver participants cared for patients who met these criteria but were not necessarily linked to any patient responders (i.e., patient and caregiver responses to surveys were not paired in the analysis of survey results). The survey included questions regarding the frequency and impact of $\mathrm{nOH}$ symptoms, management, and communication with health care providers regarding symptoms (see Additional File 1 for the full list of survey questions). Descriptive statistics are reported. The study was performed in accordance with ethical standards (e.g., 1964 Helsinki Declaration and later amendments or the comparable). As an anonymous survey, the study was exempt from ethics approval based on Code of Federal Regulations Title 45, Part 46, Subpart A, Section 46.101b, Category 2 criteria.

\section{Results}

\section{Respondents}

Demographic data are provided in Table 1. A total of 363 patients (mean age \pm standard deviation, $63.4 \pm 12.4$ years) and 128 caregivers responded to the survey. Among the caregivers, the mean \pm standard deviation age of the patient cared for was $70.7 \pm 14.8$ years; $46 \%$ provided care to a spouse or partner. Most patients experienced long-term nOH symptoms, with $48 \%$ and $21 \%$ of patient respondents reporting living with symptoms for $\geq 5$ and $\geq 10$ years, respectively (mean \pm standard deviation, $7.8 \pm 10.0$ years). Among caregivers, 59\% and 38\% reported that the patient cared for lived with symptoms for $\geq 5$ and $\geq 10$ years. PD was the most frequent underlying disorder, identified by $90 \%$ of patients and $88 \%$ of caregivers reported providing care to patients with PD. A formal diagnosis of $\mathrm{OH}$ or $\mathrm{nOH}$ was reported by $36 \%$ of patients and by $16 \%$ of caregivers. A longer duration of symptoms did not increase the proportion of patients with a formal diagnosis of $\mathrm{OH}$ or $\mathrm{nOH}$; among patients with a symptom duration of $\geq 10$ years compared with $<10$ years, 35\% (27/78) versus 36\% (102/285) reported a formal diagnosis of one of these conditions. 
Table 1 Baseline Characteristics of Survey Respondents

\begin{tabular}{|c|c|c|c|}
\hline \multirow[t]{2}{*}{ Characteristic } & \multirow{2}{*}{$\begin{array}{l}\text { Patients } \\
(n=363)\end{array}$} & \multicolumn{2}{|c|}{ Caregivers $(n=128)$} \\
\hline & & Self & Patient Being Cared for \\
\hline Men & $51 \%$ & $37 \%$ & $54 \%$ \\
\hline Mean \pm SD age, $y$ & $63.4 \pm 12.4$ & $56.2 \pm 14.9$ & $70.7 \pm 14.8$ \\
\hline White & $90 \%$ & $92 \%$ & NA \\
\hline \multicolumn{4}{|l|}{ Neurologic diagnosis $^{a}$} \\
\hline Parkinson disease & $90 \%$ & NA & $88 \%$ \\
\hline Multiple system atrophy & $10 \%$ & NA & $11 \%$ \\
\hline Pure autonomic failure & $4 \%$ & NA & $3 \%$ \\
\hline Mean \pm SD years experiencing $\mathrm{nOH}$ symptoms & $7.8 \pm 10.0$ & NA & $10.0 \pm 9.9$ \\
\hline \multicolumn{4}{|l|}{ Years living with $\mathrm{nOH}$ symptoms } \\
\hline$<1$ & $10 \%$ & NA & $5 \%$ \\
\hline $1-4$ & $42 \%$ & NA & $37 \%$ \\
\hline $5-9$ & $27 \%$ & NA & $21 \%$ \\
\hline$\geq 10$ & $21 \%$ & NA & $38 \%$ \\
\hline Formal diagnosis of $\mathrm{nOH}$ or $\mathrm{OH}$ & $36 \%$ & NA & $16 \%$ \\
\hline
\end{tabular}

$\mathrm{NA}$ not available, $\mathrm{nOH}$ neurogenic orthostatic hypotension, $\mathrm{OH}$ orthostatic hypotension

${ }^{a}$ Multiple responses could be selected; therefore, the sum of percentages is $>100 \%$

Among all respondents, $49 \%$ of patients reported that they were in fair or poor health, with $72 \%$ of caregivers reporting that the patients they provided care for were in fair or poor health. Among the subgroup with a diagnosis of PD or MSA, 34\% of patients (121/357) and 49\% of caregivers (61/125) somewhat or strongly agreed that $\mathrm{nOH}$ symptoms appeared before patients developed motor symptoms. Among patients diagnosed with PD $(n=328), 44 \%$ somewhat or strongly agreed that their $\mathrm{nOH}$ symptoms were more troublesome than their motor symptoms. Findings from caregivers of patients with PD $(n=113)$ were similar $(47 \%)$.

\section{$\mathrm{nOH}$ symptom experience and impact} nOH symptoms

The most frequently reported symptoms of $\mathrm{nOH}$ were dizziness or lightheadedness, fatigue when standing, and difficulty walking; a substantial proportion of patients reported that dizziness or lightheadedness (37\%), fatigue when standing (33\%), and difficulty walking (32\%) occurred every time or multiple times a day when they sit up, stand up, are standing for long periods of time, or have a change in position (Fig. 1). Other symptoms reported as occurring multiple times a day by $>10 \%$ of patients included blurry vision, pain running down neck

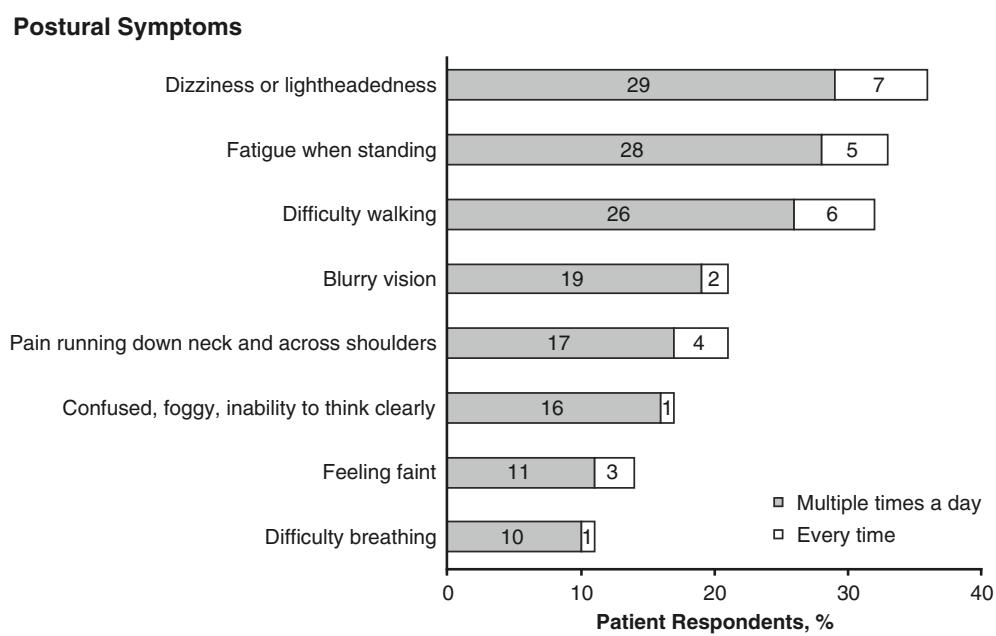

Fig. 1 Proportion of patient respondents reporting postural nOH symptoms. ${ }^{*} \mathrm{nOH}=$ neurogenic orthostatic hypotension. * Reported symptoms could be experienced upon sitting or standing up, when standing for long periods of time, or during a change in position 
and across shoulders, cognitive difficulties, faintness, and difficulty breathing (Fig. 1).

No distinct pattern emerged regarding the frequency and severity of $\mathrm{nOH}$ symptoms throughout the day (Fig. 2). When asked about conditions that exacerbated their $\mathrm{nOH}$ symptoms, the majority of patients and caregivers (61\% each) somewhat or strongly agreed that $\mathrm{nOH}$ symptoms worsened in hot and/or humid conditions. Exacerbation of $\mathrm{nOH}$ symptoms after meals was reported less frequently (27\% of patients, $34 \%$ of caregivers). Falls due to $\mathrm{nOH}$ symptoms (at least 1 in the previous year) were reported by $57 \%$ of patients (mean, 5.1 falls) and $80 \%$ of caregivers (mean, 7.8 falls).

\section{Functional impact of $\mathrm{nOH}$ symptoms}

The majority of patients (87\%) and caregivers (95\%) reported that $\mathrm{nOH}$ symptoms had an overall negative impact on patients' ability to perform everyday activities; this was categorized as severe or very severe by approximately one-fifth of patients and two-fifths of caregivers (Fig. 3). A substantial proportion of patients reported that $\mathrm{nOH}$ symptoms negatively impacted their quality of life (59\%), robbed them of their independence (42\%), or drastically changed their life (40\%). In the caregiver cohort, $75 \%$ of respondents reported that $\mathrm{nOH}$ symptoms had a negative impact on the patient's quality of life, and approximately two-thirds reported that $\mathrm{nOH}$ symptoms had robbed patients of their independence (66\%) or drastically changed their life $(65 \%)$. The symptom burden of $\mathrm{nOH}$ did not appear to be affected by the duration of symptom experience. Similar proportions of patients with $\mathrm{nOH}$ symptoms for $<10$ years and $\geq 10$ years reported that symptoms had a negative impact on their quality of life (60\% and 55\%, respectively), caused a drastic change in their life $(38 \%$ and $49 \%)$, or robbed them of their independence ( $41 \%$ and $47 \%$ ).

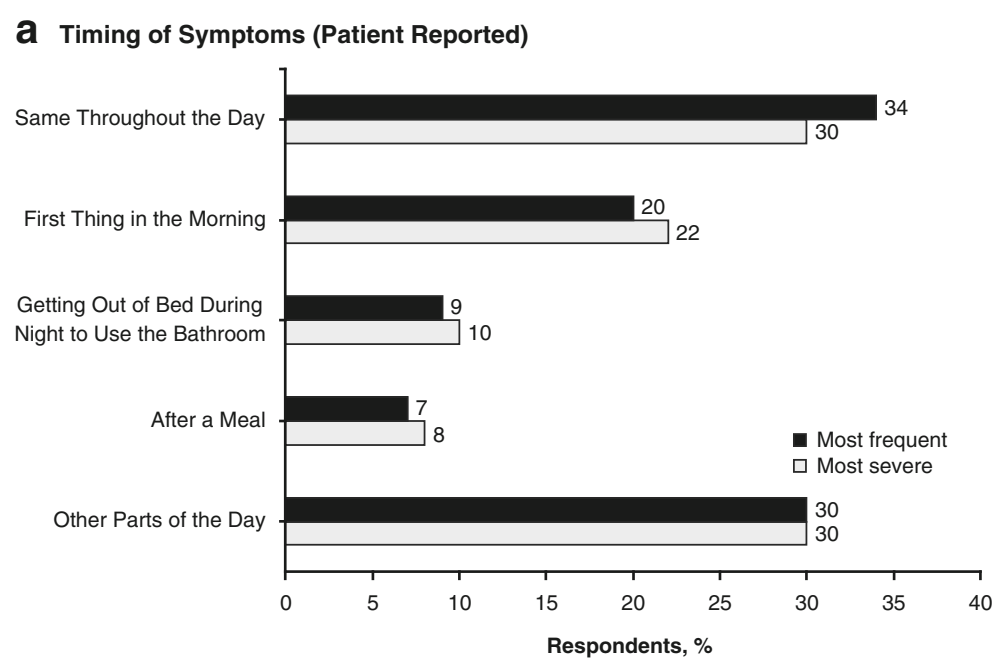

b Timing of Symptoms (Caregiver Reported)

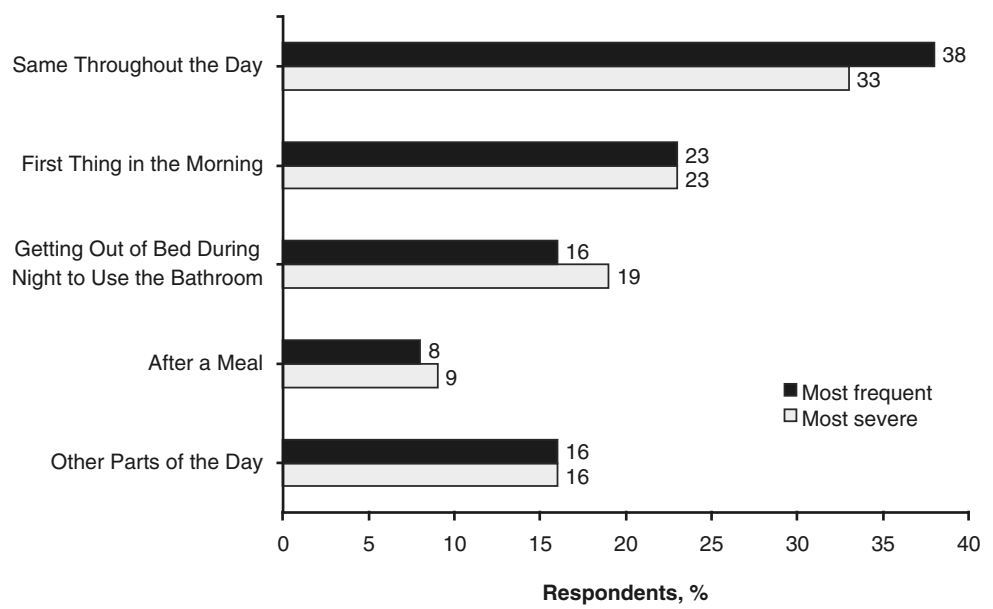

Fig. 2 Daily pattern of most frequent/severe $\mathrm{nOH}$ symptoms as reported by $\mathbf{a}$ patients and $\mathbf{b}$ caregivers. ${ }^{*} \mathrm{nOH}=$ neurogenic orthostatic hypotension. *Respondents in the patient and caregiver cohorts were not paired 


\section{a Symptom Impact by Severity (Patient Reported)}

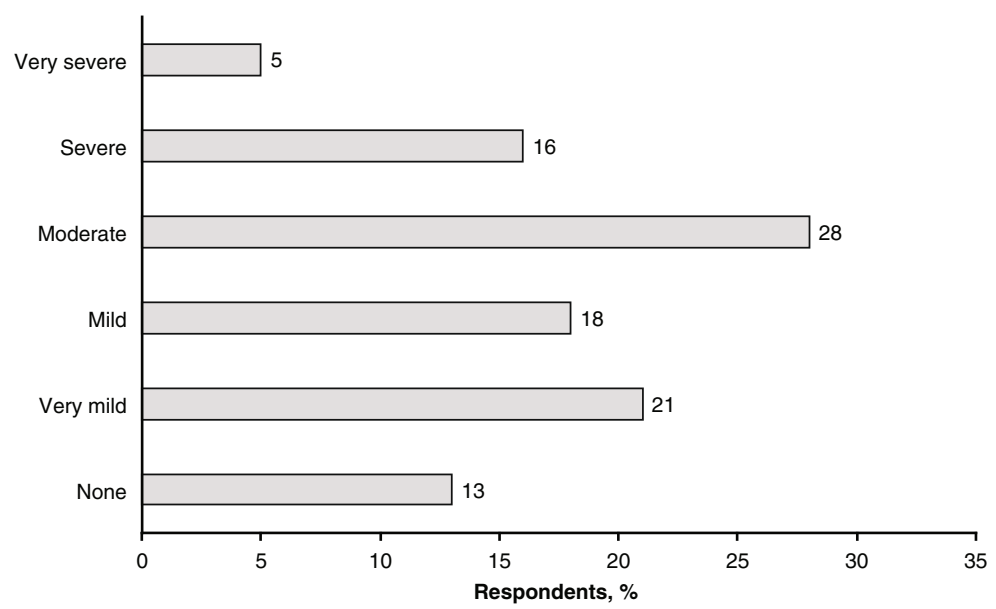

b Symptom Impact by Severity (Caregiver Reported)

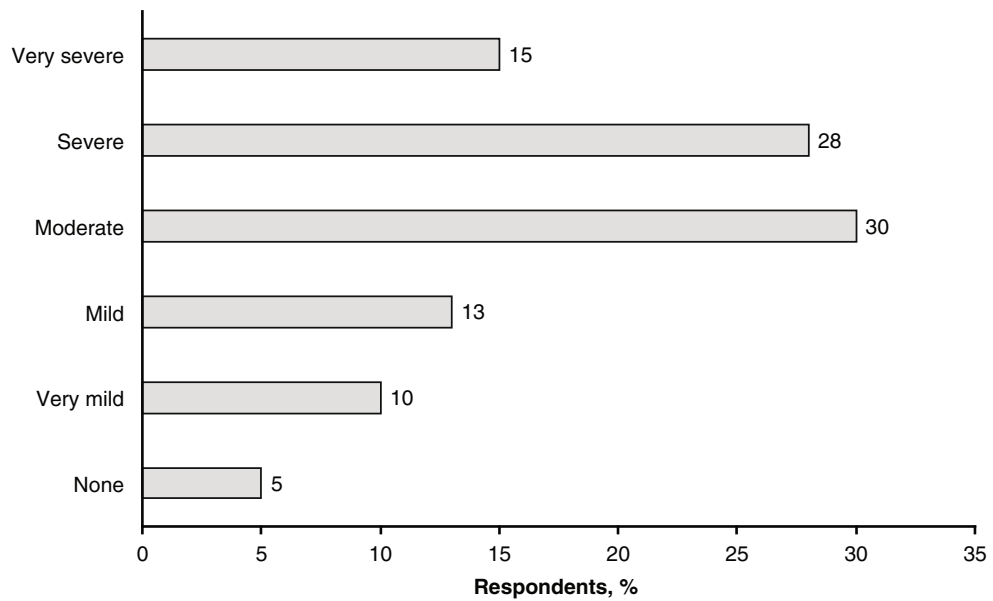

Fig. $3 \mathrm{nOH}$ symptom impact on patient daily activities as reported by a patients and $\mathbf{b}$ caregivers., ${ }^{*}+\mathrm{nOH}=$ neurogenic orthostatic hypotension. * Respondents in the patient and caregiver cohorts were not paired. ${ }^{\dagger}$ Percentages rounded to the nearest whole number

Activities that were reported as reduced or stopped because of symptoms of $\mathrm{nOH}$ by $>40 \%$ of patients were physical activity/exercise, housework, traveling, time spent out of the house to run errands or socialize, driving, hobbies, and entertaining at home (Fig. 4a). Caregivers reported that such activities were reduced or stopped in $\geq 59 \%$ of the patients they care for (Fig. $4 \mathrm{~b}$ ). More than half $(56 \%)$ of patients and $85 \%$ of caregivers reported that patients needed assistance with day-to-day activities (e.g., walking, getting out of a chair) in the past month, and up to $53 \%$ of patients and $73 \%$ of caregivers reported that some daily activities were reduced or stopped because of $\mathrm{nOH}$ symptoms.

Half of patients (50\%) somewhat or strongly agreed that nOH symptoms caused them anxiety or worry and somewhat or strongly agreed that the management of symptoms caused them to be depressed or discouraged; 39\% somewhat or strongly agreed that they really struggled to get their nOH symptoms under control. Despite the negative impact of $\mathrm{nOH}$ symptoms on functionality and quality of life, $60 \%$ of patients and $53 \%$ of caregivers somewhat or strongly agreed that patients often hide or minimize their nOH symptoms.

\section{Patient/health care provider interactions and the path to diagnosis of $\mathrm{nOH}$}

Most patients (75\%) and caregivers (77\%) somewhat or strongly agreed that they were satisfied with the quality of communication with health care providers. The health care providers most commonly seen (i.e., reported by $>20 \%$ of patients or caregivers) for the management of underlying medical conditions manifesting with $\mathrm{nOH}$ were primary care providers, movement disorder specialists, general neurologists, and general cardiologists. A delay of 6 months or more between the time of symptom onset to discussion 


\section{a Limitations (Patient Reported)}

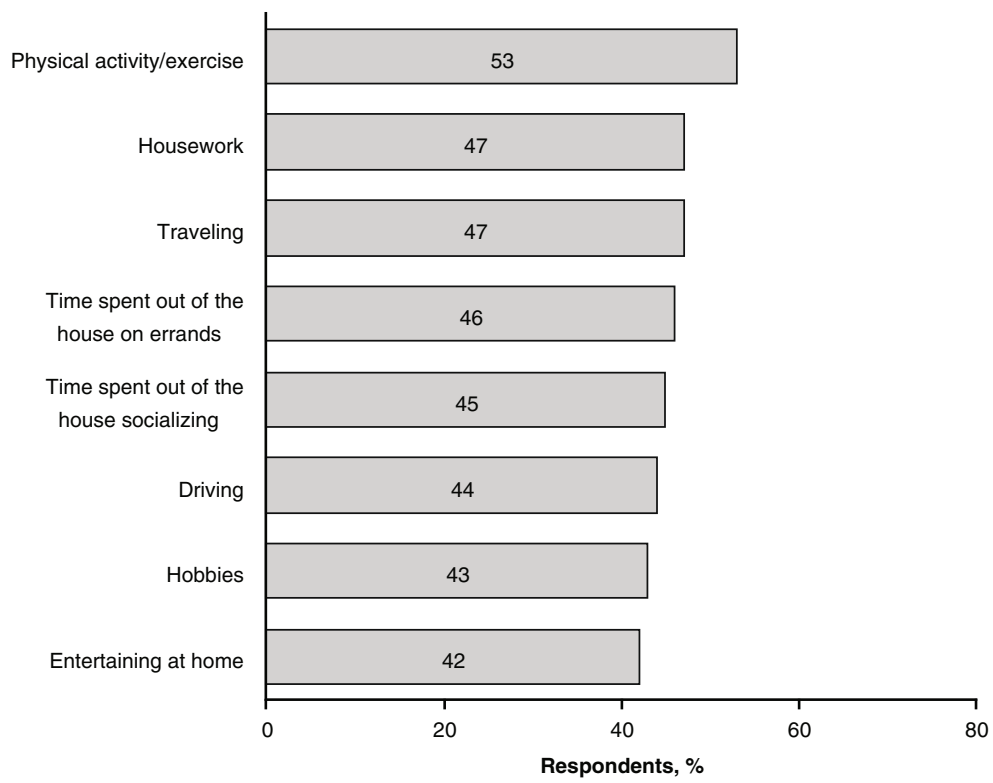

b Limitations (Caregiver Reported)

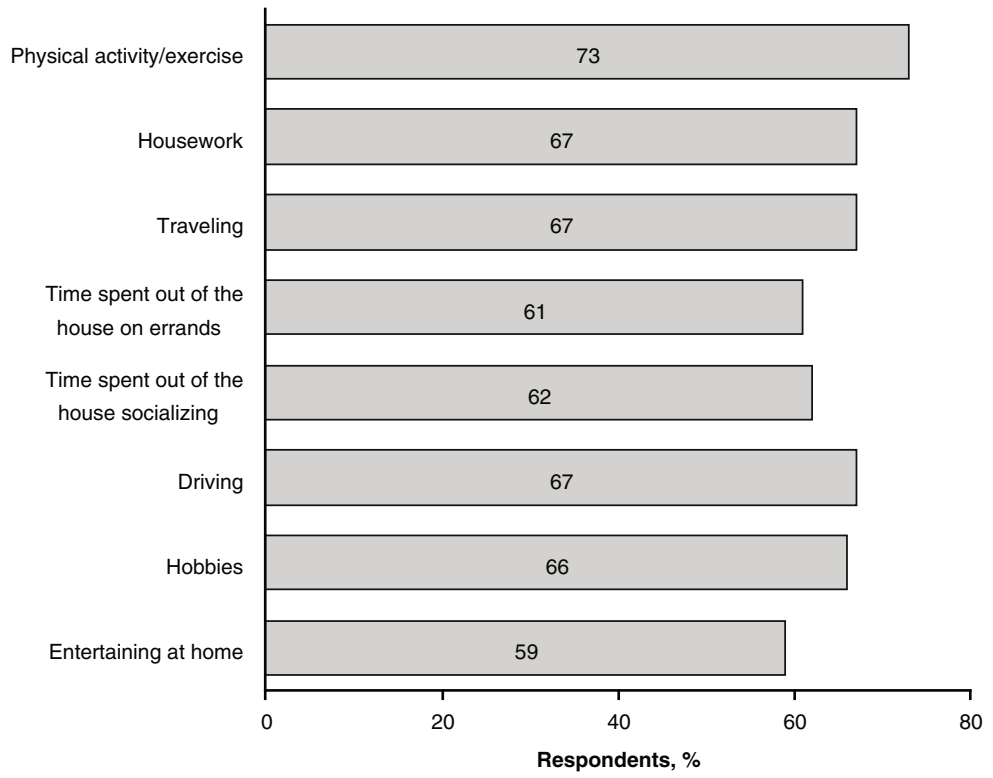

Fig. $4 \mathrm{nOH}$ symptom-related limitations on patient daily activities as reported by $\mathbf{a}$ patients and $\mathbf{b}$ caregivers.* $\mathrm{nOH}=$ neurogenic orthostatic hypotension. *Percentages represent the proportion of respondents who reported the patient reduction or stopping of the activity. Respondents in the patient and caregiver cohorts were not paired

with a health care provider was reported by $33 \%$ of patients and $41 \%$ of caregivers. Patients and caregivers (55\% each) somewhat or strongly agreed that patients did not initiate a discussion about their nOH symptoms with their health care provider unless the symptoms were severe, and $26 \%$ of patients and $39 \%$ of caregivers somewhat or strongly agreed that patients were uncomfortable talking with their health care provider about the impact of $\mathrm{nOH}$ symptoms.
Approximately one-fourth (26\%) of patients and a third (33\%) of caregivers somewhat or strongly agreed that patients had to mention their $\mathrm{nOH}$ symptoms repeatedly to their health care provider to draw attention to the problem. In the subgroup of 129 patients with a formal diagnosis of $\mathrm{nOH}$ or $\mathrm{OH}, 43 \%$ reported seeing 3 or more health care providers before being diagnosed with $\mathrm{OH}$ or $\mathrm{nOH}$. Half $(50 \%)$ of the patients who were formally diagnosed somewhat or strongly agreed that the 
path to diagnosis of $\mathrm{nOH}$ was very frustrating. However, $70 \%$ of the patients formally diagnosed with $\mathrm{OH} / \mathrm{nOH}$ somewhat or strongly agreed that management of their symptoms improved after diagnosis. Only 20 caregiver responders cared for patients who had a formal diagnosis of $\mathrm{OH} / \mathrm{nOH}$, so a similar subgroup analysis was not performed.

\section{Symptom management and treatments/interventions}

Approximately half (53\%) of patients and 62\% of caregivers somewhat or strongly agreed that they received a solution from health care providers to better manage symptoms of nOH. Interventions recommended by health care providers were avoidance of quick positional changes, increased fluid intake, adjustment of PD medications, increased salt intake, use of compression garments, elevating the head of the bed, and avoiding hot environments. Caregivers reported the same interventions with similar frequency (Table 2). A third (34\%) of patients and $45 \%$ of caregivers reported that a prescription for a medication to treat $\mathrm{nOH}$ symptoms was received; $25 \%$ of patients and $9 \%$ of caregivers reported that patients were not counseled to do anything to manage their $\mathrm{nOH}$ symptoms.

\section{Discussion}

The results of this patient and caregiver survey strongly support the premise that $\mathrm{nOH}$ symptoms have a substantial negative impact on patient function and quality of life. Data from both patients and caregivers suggest that $\mathrm{nOH}$ symptoms are associated with impaired mobility, such as difficulty with positional changes, increased frequency of falls, and decreased ability to maintain activities of daily life. Despite the high level of symptom burden and longstanding symptoms of nOH (e.g., $48 \%$ of patients with symptoms for $\geq 5$ years), the majority of respondents did not report having a formal diagnosis of $\mathrm{OH}$ or $\mathrm{nOH}$. Stratification of patients based on their duration of symptoms $(<10$ years or $\geq 10$ years $)$ did not increase the likelihood of a formal diagnosis of $\mathrm{OH}$ or $\mathrm{nOH}$. Further, there were minimal differences on the impact of $\mathrm{nOH}$ symptoms between these 2 subgroups of patients.

In this survey, the majorities of patients and caregivers did not report that nOH symptoms occurred more frequently or with greater severity first thing in the morning, after meals, or when getting out of bed during the night. Rather, more respondents indicated that $\mathrm{nOH}$ symptoms were more likely to occur or be more severe throughout the day. These results are contrary to the general clinical understanding that $\mathrm{nOH}$ symptoms are often worse in the morning and can be exacerbated after eating [13]. The lack of a distinct daily pattern for the frequency and severity of nOH symptoms emphasizes that symptoms do not always occur at a specific time or event (e.g., morning, after a meal) and is an important point of awareness for clinicians in the evaluation of patients for $\mathrm{nOH}$.

This survey also revealed factors that may contribute to the relatively low rate of formal $\mathrm{nOH}$ diagnosis. The majority of patients reported hiding or minimizing their $\mathrm{nOH}$ symptoms. Further, patients indicated that they were uncomfortable discussing the impact of symptoms with health care providers and did not discuss the impact of their symptoms unless they were severe. Finally, some patients and caregivers reported that symptoms had to be discussed several times in order to draw them to the attention of the treating provider.

Reticence of patients to share symptoms with caregivers and health care providers has been observed with depression, pain, and other chronic conditions [14-16]. Patients may hide or minimize their $\mathrm{nOH}$ symptoms because they view symptoms as a sign of weakness or because they are embarrassed, in denial, do not want to be a "bother" to others, or other reasons [14-16]. Of note, among patients in the current survey with a diagnosis of $\mathrm{nOH}$, many (70\%) perceived that their symptoms had improved after

Table 2 Recommended Interventions for $\mathrm{nOH}$ by Health Care Providers

\begin{tabular}{|c|c|c|}
\hline Intervention & Patients Reporting $(\mathrm{n}=363$ ) & Caregivers Reporting $(n=128)$ \\
\hline Avoid quick positional changes & $49 \%$ & $48 \%$ \\
\hline Increase fluid intake & $47 \%$ & $52 \%$ \\
\hline Adjust PD medication & $28 \%$ & $43 \%$ \\
\hline Increase salt intake & $27 \%$ & $20 \%$ \\
\hline Wear compression stockings and/or abdominal binders & $24 \%$ & $27 \%$ \\
\hline Elevate head of the bed & $22 \%$ & $28 \%$ \\
\hline Avoid heated environments & $16 \%$ & $16 \%$ \\
\hline Adjust or discontinue blood pressure or heart medications & $15 \%$ & $28 \%$ \\
\hline $\begin{array}{l}\text { Physical counter maneuvers (e.g., standing up and crossing legs, } \\
\text { standing up and squeezing hands tightly) }\end{array}$ & $12 \%$ & $13 \%$ \\
\hline No intervention recommended & $25 \%$ & $9 \%$ \\
\hline
\end{tabular}

$\mathrm{nOH}$ neurogenic orthostatic hypotension, $P D$ Parkinson disease 
receiving the diagnosis. However, a substantial proportion of patients were not counseled on how to manage $\mathrm{nOH}$, were not prescribed medication for $\mathrm{nOH}$ symptoms, and felt they did not have adequate control of their $\mathrm{nOH}$ symptoms.

Inadequate management of $\mathrm{nOH}$ symptoms appears to be a cause of distress for many patients. Nonpharmaceutical treatment recommendations for $\mathrm{nOH}$ include ensuring adequate salt and fluid intake, avoiding rapid postural changes, adjusting medications, and sleeping with the head of the bed elevated [5, 17]. Patients and caregivers indicated that such nonpharmaceutical interventions were commonly recommended and frequently helpful. However, a substantial proportion of respondents indicated that they did not achieve symptomatic relief, and only a third of patients indicated that they received a prescription for a medication to treat symptoms of $\mathrm{nOH}$. These results provide greater understanding of the disease burden of $\mathrm{nOH}$. Previously, a negative impact of $\mathrm{nOH}$ symptoms was found in a single-center study of 141 inpatients with PD, in which $53 \%$ of patients reported that orthostatic dizziness had "a lot" or "very much" impact on daily life [11]. A 2-center study of patients with PD has suggested that both symptomatic $(n=14)$ and asymptomatic $(n=23)$ $\mathrm{nOH}$ were associated with worse measures of functionality and quality of life compared with patients with PD but without $\mathrm{nOH}(n=84)$ [18]. Our study adds to the evidence by inclusion of data from a larger cohort of patients $(N=363)$ who experience nOH symptoms due to a variety of underlying conditions, including MSA and pure autonomic failure (however, most of the cohort reported a PD diagnosis). Further, to the best of our knowledge, our study is the first to investigate the impact of $\mathrm{nOH}$ from both the patient and caregiver perspective. $\mathrm{nOH}$ is one of the many manifestations of autonomic dysfunction, and patients may also have their quality of life affected by other symptoms, including gastrointestinal dysfunction (e.g., dysphagia, constipation), bladder dysfunction (e.g., urinary urgency, incontinence), sexual dysfunction (e.g., erectile dysfunction), cardiovascular dysfunction (e.g., hypertension, supine hypertension), and thermoregulation and sweating abnormalities (e.g., dyshidrosis) $[19,20]$.

Survey methodology has inherent limitations, such as selection bias and recall bias. Patient and caregiver responses were not paired; therefore, it is not possible to draw conclusions regarding consistency of responses between patients and their caregivers. Pairing each patient's response with their caregiver's response for each question should be considered in future studies. Many participants (64\% of patients, $84 \%$ of caregivers) did not have a formal diagnosis of $\mathrm{OH}$ or nOH; therefore, the survey may underestimate the burden of symptoms of those formally diagnosed with $\mathrm{OH}$ or $\mathrm{nOH}$.

\section{Conclusions}

The findings from this survey underscore a significant symptom burden associated with $\mathrm{nOH}$. Many patients have a delay or lack of diagnosis of $\mathrm{nOH}$, which creates diagnostic uncertainty and slows symptom management. As a consequence of this under-recognition of $\mathrm{nOH}$, patients may face an increased risk of falls and associated morbidity $[21,22]$. This study highlights the need for a more timely diagnosis of nOH. Improved patient/provider communication about symptoms of $\mathrm{nOH}$ may facilitate more timely and appropriate intervention for these patients. Overall, heightened awareness regarding $\mathrm{nOH}$ and its symptom burden should be an educational priority for patients, as well as for their caregivers and for health care providers.

\section{Additional file}

Additional file 1: Online Survey for Patient and Caregiver

Characterization of Neurogenic Orthostatic Hypotension Symptoms and Impact (DOCX $60 \mathrm{~kb})$

\section{Abbreviations}

BP: blood pressure; MSA: multiple system atrophy; NA: not available; $\mathrm{nOH}$ : neurogenic orthostatic hypotension; $\mathrm{OH}$ : orthostatic hypotension; PD: Parkinson disease

\section{Acknowledgments}

The authors received editorial assistance from CHC Group (North Wales, PA), which was supported by Lundbeck.

\section{Funding}

The data reported were derived from a survey that was supported by Lundbeck. The sponsor participated in the design of this study, data analysis and interpretation, and in the preparation of the manuscript.

\section{Availability of data and materials}

Data sets analyzed during the current study are available from the corresponding author upon reasonable request.

\section{Authors' contributions}

DOC, CHA, LAH, and CG participated in survey design and interpretation of data. Each author was involved in drafting, reviewing, and final approval of the manuscript for publication. All authors read and approved the final manuscript.

\section{Ethics approval and consent to participate}

The study was performed in accordance with ethical standards (e.g., 1964 Helsinki Declaration and later amendments or the comparable). Respondents were selected from individuals who agreed to participate in Harris Poll online surveys or were members of certain advocacy organizations who actively decided to participate in the survey. For research in which participants are intended to remain anonymous, Harris Poll uses tools and methods to ensure that there is no reasonable possibility of identifying an individual participant in the reports created (e.g., individual responses collected are combined to produce "aggregated" reports). As an anonymous survey, the study was exempt from ethics approval based on Code of Federal Regulations Title 45, Part 46, Subpart A, Section 46.101b, Category 2 criteria.

Consent for publication

Not applicable.

\section{Competing interests}

DOC receives grant support from the National Institutes of Health and the Michael J. Fox Foundation for Parkinson's Research; is a site investigator for 
clinical trials sponsored by Vaccinex, AbbVie, CHDI, and Auspex/Teva Neuroscience; and has received personal remuneration from Lundbeck, Teva Neuroscience, Acadia, and AbbVie for consulting, advisory board participation, and speaking honoraria. CHA has received research funding from the National Institutes of Health and the Michael J. Fox Foundation for Parkinson's Research and consulting fees from Acadia, Acorda, Adamas, Cynapsus, Jazz, Lundbeck, Minerva, Neurocrine, and Sunovion. LAH is an employee of Lundbeck Medical Affairs. CG has served on advisory boards for Lundbeck and Pfizer and on data safety monitoring boards for Janssen and Astellas, and has received grants from Grifols and Celgene.

\section{Publisher's Note}

Springer Nature remains neutral with regard to jurisdictional claims in published maps and institutional affiliations.

\section{Author details}

'Department of Neurology, Vanderbilt University Medical Center, 1161 21st Avenue South A-0118, Nashville, TN 37232, USA. ${ }^{2}$ Parkinson's Disease and Movement Disorders Center, Department of Neurology, Mayo Clinic College of Medicine, Mayo Clinic, 13400 East Shea Boulevard, Scottsdale, AZ 85259, USA. ${ }^{3}$ Medical Affairs, Lundbeck, 6 Parkway North, Deerfield, IL 60015, USA. ${ }^{4}$ Department of Neurology, Beth Israel Deaconess Medical Center, Harvard Medical School, 330 Brookline Avenue, Boston, MA 02215, USA

Received: 6 April 2018 Accepted: 15 August 2018

Published online: 25 August 2018

\section{References}

1. Freeman R, Wieling W, Axelrod FB, Benditt DG, Benarroch E, Biaggioni I, et al. Consensus statement on the definition of orthostatic hypotension, neurally mediated syncope and the postural tachycardia syndrome. Clin Auton Res. 2011;21:69-72.

2. Ha AD, Brown $\mathrm{CH}$, York MK, Jankovic J. The prevalence of symptomatic orthostatic hypotension in patients with Parkinson's disease and atypical parkinsonism. Parkinsonism Relat Disord. 2011:17:625-8.

3. Metzler M, Duerr S, Granata R, Krismer F, Robertson D, Wenning GK. Neurogenic orthostatic hypotension: pathophysiology, evaluation, and management. J Neurol. 2013;260:2212-9.

4. Senard JM, Rai S, Lapeyre-Mestre M, Brefel C, Rascol O, Rascol A, et al. Prevalence of orthostatic hypotension in Parkinson's disease. J Neurol Neurosurg Psychiatry. 1997;63:584-9.

5. Gibbons CH, Schmidt P, Biaggioni I, Frazier-Mills C, Freeman R, Isaacson S, et al. The recommendations of a consensus panel for the screening, diagnosis, and treatment of neurogenic orthostatic hypotension and associated supine hypertension. J Neurol. 2017;264:1567-82.

6. Goldstein DS, Sharabi Y. Neurogenic orthostatic hypotension: a pathophysiological approach. Circulation. 2009;119:139-46.

7. Shibao C, Lipsitz LA, Biaggioni I. ASH position paper: evaluation and treatment of orthostatic hypotension. J Clin Hypertens (Greenwich). 2013;15:147-53.

8. McDonald C, Pearce M, Kerr SR. Newton J. A prospective study of the association between orthostatic hypotension and falls: definition matters. Age Ageing. 2017:46:439-45.

9. Ooi WL, Hossain M, Lipsitz LA. The association between orthostatic hypotension and recurrent falls in nursing home residents. Am J Med. 2000;108:106-11.

10. Fereshtehnejad SM, Lokk J. Orthostatic hypotension in patients with Parkinson's disease and atypical parkinsonism. Parkinsons Dis. 2014;2014 475854.

11. Magerkurth C, Schnitzer R, Braune S. Symptoms of autonomic failure in Parkinson's disease: prevalence and impact on daily life. Clin Auton Res. 2005; 15:76-82

12. McDonell KE, Shibao CA, Claassen DO. Clinical relevance of orthostatic hypotension in neurodegenerative disease. Curr Neurol Neurosci Rep. 2015;15:78.

13. Freeman R. Clinical practice. Neurogenic orthostatic hypotension. N Engl J Med. 2008;358:615-24.

14. Cagle J, Bunting M. Patient reluctance to discuss pain: understanding stoicism, stigma, and other contributing factors. J Soc Work End Life Palliat Care. 2017;13:27-43.

15. Sawada N, Uchida H, Watanabe K, Kikuchi T, Suzuki T, Kashima H, et al. How successful are physicians in eliciting the truth from their patients? A largescale internet survey from patients' perspectives. J Clin Psychiatry. 2012;73: 311-7.
16. Clarke LH, Bennett E. "you learn to live with all the you": gender and the experience of multiple chronic conditions in later life. Ageing Soc. 2013;33: 342-60.

17. Isaacson SH, Skettini J. Neurogenic orthostatic hypotension in Parkinson's disease: evaluation, management, and emerging role of droxidopa. Vasc Health Risk Manag. 2014;10:169-76.

18. Merola A, Romagnolo A, Rosso M, Lopez-Castellanos JR, Wissel BD, Larkin S, et al. Orthostatic hypotension in Parkinson's disease: does it matter if asymptomatic? Parkinsonism Relat Disord. 2016;33:65-71.

19. Palma JA, Kaufmann H. Treatment of autonomic dysfunction in Parkinson disease and other synucleinopathies. Mov Disord. 2018;33:372-90.

20. Mathias C. Autonomic diseases: clinical features and laboratory evaluation. J Neurol Neurosurg Psychiatry. 2003;74:iii31-41.

21. Craig GM. Clinical presentation of orthostatic hypotension in the elderly. Postgrad Med J. 1994;70:638-42.

22. Shaw BH, Claydon VE. The relationship between orthostatic hypotension and falling in older adults. Clin Auton Res. 2014;24:3-13.
Ready to submit your research? Choose BMC and benefit from:

- fast, convenient online submission

- thorough peer review by experienced researchers in your field

- rapid publication on acceptance

- support for research data, including large and complex data types

- gold Open Access which fosters wider collaboration and increased citations

- maximum visibility for your research: over $100 \mathrm{M}$ website views per year

At BMC, research is always in progress.

Learn more biomedcentral.com/submissions 